$\angle$ Research Square

\section{A Task-shifting and Family-focused Approach Towards Mental Health Care for Youth Living in Refugee Camps}

Florian Scharpf ( $\sim$ florian.scharpf@uni-bielefeld.de)

Bielefeld University: Universitat Bielefeld https://orcid.org/0000-0002-2878-9088

Tobias Hecker

Bielefeld University: Universitat Bielefeld

Research in practice

Keywords: Mental health care, refugee youth, refugee camps, task-shifting, family-focused

Posted Date: January 28th, 2021

DOI: https://doi.org/10.21203/rs.3.rs-153988/v1

License: @) (1) This work is licensed under a Creative Commons Attribution 4.0 International License. Read Full License 


\section{Abstract}

Background: In humanitarian emergencies with few specialist resources for mental health care, it is a practical and ethical necessity to allocate available resources to interventions that target youth most in need of support and address contextually relevant factors of influence. Based on the findings of an extensive epidemiological observational study with 230 Burundian refugee youth aged 7 to 15 years and both their caregivers in three refugee camps, we propose a multi-layered mental health service model that is characterized by task-shifting from professionals to non-professionals, close-meshed collaboration between different agencies within camps and inclusion of families at all stages.

Discussion: The model prioritizes the identification of youth with clinically relevant mental health problems through extensive screening, who are then provided with trauma- and/or family-focused interventions depending on a more detailed assessment of needs. We emphasize the importance of incorporating evidence-based interventions and evaluating all model components and discuss caveats and limitations concerning the implementation of the model.

Conclusion: The paper aims to sensitize researchers and practitioners in the field of mental health care for youth in refugee and other humanitarian settings to the importance of conducting epidemiological assessments of the specific need for interventions and of contextually relevant intervention targets.

\section{Introduction}

Refugee children and adolescents living in refugee camps in low- and middle-income countries are at an increased risk of developing debilitating mental health problems, such as posttraumatic stress disorder (PTSD), internalizing problems including depression and anxiety and externalizing problems including aggressive and antisocial behavior, as a result of their exposure to violent conflict in their home countries and to ongoing hardships in the camps (Reed et al., 2012; Scharpf, Kaltenbach, Nickerson, et al., 2020; Vossoughi et al., 2018). However, the financial and personnel resources for mental health care in these settings are often extremely limited (de Jong et al., 2015). In an effort to maximize the number of children receiving adequate mental health care despite scarce resources in humanitarian emergencies, a number of guidelines and models have been developed (Eruyar et al., 2018; Inter Agency Standing Committee (IASC), 2007; Jordans et al., 2010; Saltzman et al., 2003). The common idea underlying these approaches is that mental health and psychosocial care is provided on multiple layers, which can be illustrated in form of a pyramid. Although these layers are ideally put in place concurrently, they are hierarchically organized, from the provision of basic services and security at the bottom through broad-scale resilience-building activities for communities and low-level interventions provided by non-specialists to specialized services focusing on individuals suffering from severe mental health problems at the top of the pyramid (Inter Agency Standing Committee (IASC), 2007; Jordans et al., 2010). In this paper, we argue in favor of focused interventions targeted at children and adolescents with clinically relevant mental health problems over universal approaches addressing large numbers of youth in an indiscriminate manner for two reasons: a more efficient use of limited resources for mental health care and avoiding harmful effects of non-targeted interventions.

While available stepped-care models provide a comprehensive and broadly applicable framework for the planning and delivery of interventions to refugee and other conflict-affected children, their features and implementation also depend to a large extent on the specific context, needs and resources (Jordans et al., 2010). A general imperative for any kind of intervention is that they should first establish the need for an intervention in a given setting through an epidemiological assessment and assess contextually and culturally relevant risk and protective factors as intervention targets (de Jong et al., 2015). An obvious argument for this approach is to enable the allocation of scarce resources to those who are really in need of interventions (Stevens \& Gillam, 1998). Given the high prevalence rates of mental disorders often found among children and adults in most displacement settings in low-and middle-income countries (Morina et al., 2018; Vossoughi et al., 2018), large-scale and low-intensity interventions appear to make the most efficient use of limited available resources. However, epidemiological prevalence estimates highly vary based on the specific context and methodological factors such as sampling and assessment methods, with lower rates observed in random samples assessed with structured clinical interviews (Kien et al., 2019). In settings with lower yet still considerable prevalence rates, a targeted approach may be more suitable to address those youth who are really in need of mental health care. Another less obvious argument for a priori epidemiological assessments of a population`s need and relevant factors of influence refers to possible negative treatment effects for subgroups of children in areas of armed conflict (Jordans et al., 2016). For instance, in unstable and stressful settings, universal school-based programs may also undermine the natural recovery of children suffering from clinically relevant symptoms of PTSD, depression and anxiety and thus be harmful in fact (Ertl \& Neuner, 2014; Tol et al., 2014).

In early 2018 , we set out to conduct an epidemiological and observational cross-sectional study to assess the prevalence of mental health problems, i.e. the need for interventions, and relevant contributing factors among Burundian refugee families living in refugee camps in Western Tanzania. After briefly describing the overall study context we summarize the main findings of the study, from which we then derive a mental health service model for Burundian refugee youth.

\section{Overall Study Context}

Having seen several phases of extreme inter-ethnic violence since its independence in 1962, including a long-lasting civil war from 1993 until 2005 (Uvin, 2009), the small, land-locked East African country of Burundi plunged into the latest crisis in April 2015, when the then president announced to stay in power for an illegitimate third term. Violence and atrocities committed by members of the ruling political party towards perceived opponents, including abductions, extrajudicial killings and torture, caused more than 400,000 Burundians to flee to neighbouring countries, making Burundi the $10^{\text {th }}$ largest source country for refugees worldwide at the end of 2017 (Human Rights Watch, 2017; UNHCR, 2018b). Tanzania hosted the largest number of Burundian refugees with over 250,000 people as of October 2017, 58\% of whom were children (UNHCR, 2018a). The refugees were resettled in three large refugee camps, Nyarugusu, Nduta and Mtendeli, in the Kigoma region in Western Tanzania close to the border to Burundi. Notwithstanding the scale of the Burundian refugee crisis, it received least fundina hv international donors of all refunee situations worldwide, which translated into a lack of resources for the provision of food, shelter, health Loading [MathJax]/jax/element/mml/optable/Latin1Supplement.js 
care, education and other services in the camps (Reliefweb, 2018). The International Rescue Committee (IRC), the main provider for mental health and psychosocial services in the three refugee camps, employs eight mental health professionals (four psychologists in Nduta, two in Nyarugusu and two in Mtendeli; no psychiatrists) for all Burundian refugees, implying a ratio of one psychologist for about 30000 people. Currently, there are only limited and few specific mental health interventions targeting children and adolescents in the camps, namely psychosocial support and socio-emotional learning groups at school, play therapy and counselling (personal communication).

\section{Summary of study procedure and main findings}

The study was conducted between January and May 2018 in the three camps. We included family triads consisting of the mother or primary female caregiver, the father or primary male caregiver (in the following referred to as mothers and fathers) and the oldest child in primary school age, i.e. between 7 and 15 years. In each camp, we applied a combined systematic and random sampling approach (Scharpf et al., 2019), which ensured representativity for twocaregiver-households in the camps and provided epidemiologically relevant data. We conducted individual structured clinical interviews with mothers, fathers and children on their traumatic experiences, mental health problems and on factors potentially contributing to family members

mentalhea $<h$. The $\mu<i-\in f$ or mantstructured $\int$ erviewassessmentwasconsred $\rightarrow$ provm or evalatacompared $\rightarrow$ self - ad min isteredqut s mental health (Fazel et al., 2005). In addition, we conducted a small survey on childrens and parents awareness and use of existing mental health and psychosocial services in the camps as well as their coping resources. We took the following measures in order to increase the appropriateness of the assessment for the camp context and the cultural background of the sample: qualitative evaluations of the study instruments by members of the refugee communities in each camp who were also employed as research assistants, use of translators from the refugee community to increase participants comprehension of questions and a pilot assessment in the first camp (Scharpf et al., 2019; Scharpf, Mkinga, Neuner, et al., 2020).

The assessment of youth revealed a one-month prevalence of $5.7 \%$ for PTSD and a prevalence of $10.9 \%$ for increased levels of internalizing and externalizing problems (Scharpf et al., 2019). According to mothers and fathers reports, levels of increased internalizing and externalizing problems were $15.9 \%$ and $11.5 \%$, respectively. Interviews with parents revealed one-month prevalence of $32.6 \%$ for PTSD among mothers and of $29.1 \%$ among fathers, while $90.9 \%$ of mothers and $83.9 \%$ of fathers scored above the cut-off for general psychological distress within the past seven days (Scharpf et al., 2019).

While youthsl if etimeexposure $\rightarrow$ traumaticexperienceswasthestron $\geq$ stpredic $\rightarrow$ roftheirpsychopathology, higher $\leq$ velsof $\perp$ hmothers and fathers

psychopathologyadditionallycontributed $\rightarrow$ theirpsychopathology(Scharpf, Mk $\in$ ga, Neu $\neq r$, etal. , 2020). F or mothers, thisassociationwi s more insecure attachment representations of the mother-child relationship and higher levels of maltreatment by mothers as reported by youth. Moreover, higher levels of parental maltreatment were directly and indirectly (through youth

spsychopathology) $l \in \mathrm{ked} \rightarrow \mathrm{m}$ or eseveremem or ydeficits(Scharpf, Muel $\leq r$, Masath, etal. , 2020), whichmayhavelong - term $\neg$ ativeconء s externalizing problems (Scharpf, Mkinga, Masath, et al., 2020). However, youth who reported to have higher quality friendships endorsed lower levels of PTSD symptoms and externalizing problems. The results of the survey on family members' use of existing mental health and psychosocial services as well as informal coping resources are displayed in Table 1. 


\begin{tabular}{|c|c|c|c|}
\hline & $\begin{array}{l}\text { Children } \\
(n= \\
211)\end{array}$ & $\begin{array}{l}\text { Mothers } \\
(n= \\
207)\end{array}$ & $\begin{array}{l}\text { Fathers } \\
(\mathrm{n}= \\
202)\end{array}$ \\
\hline \multicolumn{4}{|c|}{$\begin{array}{l}\text { Awareness and engagement with non-governmental organizations (NGOs) providing mental health and psychosocial } \\
\text { support, \% ( })\end{array}$} \\
\hline Are you aware of these NGOs? & $\begin{array}{l}43.5 \\
(100)\end{array}$ & $\begin{array}{l}71.8 \\
(150)\end{array}$ & $\begin{array}{l}71.3 \\
(144)\end{array}$ \\
\hline Have you ever attended these NGOs? & $6.6(14)$ & $\begin{array}{l}34.4 \\
(72)\end{array}$ & $34.2(69)$ \\
\hline If yes, were you satisfied with the support you received? & $64.3(9)$ & $\begin{array}{l}73.6 \\
(53)\end{array}$ & $46.4(32)$ \\
\hline \multicolumn{4}{|c|}{ Coping resources: When you have mental health problems ${ }^{a}$, do you... \% (n) } \\
\hline ...talk to family members and relatives? & $\begin{array}{l}92.4 \\
(195)\end{array}$ & $\begin{array}{l}22.7 \\
(47)\end{array}$ & $32.7(66)$ \\
\hline ...talk to your spouse (only for parents)? & & $\begin{array}{l}52.2 \\
(108)\end{array}$ & $\begin{array}{l}66.8 \\
(135)\end{array}$ \\
\hline ...talk to religious leaders? & $\begin{array}{l}24.2 \\
(51)\end{array}$ & $\begin{array}{l}33.3 \\
(69)\end{array}$ & $40.1(81)$ \\
\hline ...talk to close friends? & $\begin{array}{l}64.5 \\
(136)\end{array}$ & $42(87)$ & $48.5(98)$ \\
\hline ...talk to community leaders? & $\begin{array}{l}13.3 \\
(28)\end{array}$ & $\begin{array}{l}26.6 \\
(55)\end{array}$ & $27.7(56)$ \\
\hline ...engage in prayers? & $\begin{array}{l}61.1 \\
(129)\end{array}$ & $56(116)$ & $\begin{array}{l}52.0 \\
(105)\end{array}$ \\
\hline ...engage in music, sports or other leisure activities? & $\begin{array}{l}66.4 \\
(140)\end{array}$ & $\begin{array}{l}34.8 \\
(72)\end{array}$ & $46.0(93)$ \\
\hline
\end{tabular}

\section{Model Presentation}

Based on these key findings, we propose a mental health service model for Burundian families living in the refugee camps. In line with the Inter-Agency Standing Committee (IASC) Guidelines for Mental Health and Psychosocial Support (2007) and related stepped care models for refugee and conflict-affected children (Eruyar et al., 2018; Jordans et al., 2010), the model aims to provide mental health care to children and adolescents across multiple layers and different ecological contexts (individual, family, community). However, in view of the low prevalence of mental health problems among youth in the camps and the important role of both trauma exposure and family-related factors for youth smentalhea $<h$, wearguetht if $y \in$ gyouthwithcl $\in$ icallyre $\leq$ vantmentalhea $<$ hprob $\leq$ ms and provgthemwithtrauma- and family-foc $s$ base in the original multi-layered model, should be neglected. In contrast, displacement-related stressors should be addressed as they have direct and indirect impacts on families and children (Miller \& Rasmussen, 2017). However, stronger focus should be placed on identifying those children suffering from severe mental health problems, who should then receive focused mental health care. Although this model refers to the specific context of Burundian refugees in Tanzanian camps, it may also be applicable to other conflict-affected and resource-poor settings with rather low prevalence rates of mental disorders among youth, e. g. in North Uganda (3.3\% for PTSD and 9.6\% for emotional and behavioral problems; Saile et al., 2016).

Considering the limited specialist resources for mental health care in the camps, a crucial element on all layers of the proposed model is task-shifting, i.e. the transfer of skills from mental health professionals to trained non-specialists, such as community workers, teachers and nurses (Hodes \& Vostanis, 2018; Silove et al., 2017). This approach is cost-effective, sustainable and increases the potential for broad dissemination of interventions (Fazel, 2018; Silove et al., 2017). Moreover, given the important role of parental factors for children`s mental health, the involvement of parents or caregivers at all levels is another essential feature of the model. The model is graphically displayed in Figure 1. The individual layers of the model and possible interventions at each layer are described in more detail in the following.

\section{Identification and targeting}


The base layer comprises all activities that aim at identifying those children who are suffering from severe mental health problems. This requires a broad approach and a close-meshed collaboration between different organizations and services, e.g. education, child protection, physical and mental health care. The most important activity in this layer is screening children for mental health problems including PTSD symptoms, internalizing and externalizing problems, which can be conducted by trained para-professionals such as teachers, community mobilizers, nurses and social workers in their respective settings. It is crucial that screening instruments are locally validated (Hall et al., 2014). Youth who are screened positive can then be interviewed by a trained counsellor to establish a diagnosis and be referred to an appropriate intervention. For instance, Catani et al. (2009) followed such an approach in a treatment study with Sri Lankan youth who had been affected by war and tsunami: After an initial screening in schools, trained local counsellors conducted clinical interviews to assess the presence of PTSD among youth and delivered Narrative Exposure Therapy for children (KIDNET) or a meditation-relaxation intervention to those with a diagnosis.

The findings of the survey further point to the importance of increasing youth saware $\neq$ ssofservices and reduc $\in$ giriers $\rightarrow$ aessparticarly $\in$ parentswhoarema $\in$ lyresponsib $\leq f$ or $\in$ itiat $\in$ gcontactwith or ganizati understanding and make it easier for them to identify children suffering from problems. Moreover, working together with existing informal resources providing psychosocial support, e.g. traditional healers, religious groups or community elders, can be helpful in identifying and referring children in need of treatment.

\section{Interventions}

The identification of children and adolescents in need of intervention enables an effective and efficient allocation of available resources on the next layer of interventions. Our studies revealed youthstraumaexposure and family - relatedfac $\rightarrow$ rs, i. e. $\perp$ hparents psychopathology and maltreatment by parents, as promising targets for interventions. In view of these findings, we emphasize the need for both trauma-focused and family-level interventions taking into account parents` well-being and aiming at reducing child maltreatment. Interventions that can be provided by non-specialist facilitators without cost- and time-intensive training may be most suitable. Most importantly, only evidence-based interventions should be included in the model, which need to be constantly evaluated (Fazel, 2018; Wessells, 2009).

With regard to trauma-focused interventions, narrative exposure therapy (NET) and its adaptation for children (KidNET) have been shown to be effective in reducing PTSD symptoms among refugee and war-affected children and adults in low- and middle-income settings (Neuner et al., 2004; Robjant \& Fazel, 2010). It is a short and pragmatic treatment that can be provided by trained lay counsellors even without a mental health background and can be easily disseminated in low-resource settings through a "train-the-trainer" approach (Jacob et al., 2014; Neuner et al., 2008). Trauma-focused cognitive behavioral therapy (TF-CBT; Cohen et al., 2016) may be another promising intervention in this setting. This treatment model has the advantage that it also includes parents and caregivers through individual and joint parent-child sessions and addresses several risk factors identified by our studies, for example supporting children and parents in processing their own and joint traumatic experiences, improving the parent-child relationship and teaching parenting skills that may prevent child maltreatment (Cohen et al., 2016). TF-CBT has been evaluated as a group-based and culturally modified intervention provided by local facilitators in randomized controlled trials with war-affected adolescents in DR Congo showing reductions in PTSD symptoms, internalizing and externalizing problems compared to wait-list controls (McMullen et al., 2013; O'Callaghan et al., 2013). Although a group format implies an efficient use of resources and may be beneficial through normalizing problems and providing peer support, the creation of trauma narratives should be done in individual sessions to avoid vicarious traumatization within the group (McMullen et al., 2013).

Based on a more detailed diagnostic assessment of children following identification, it is possible to tailor the intervention to the individual child sspec if icprob $\leq$ mareas. Acommone $\leq$ mentsapproachallows $\rightarrow$ comb $\in$ ed $\Leftrightarrow$ erenttreatmente $\leq$ ments $\in$ af $\leq \xi b \leq$ ma $\cap$ erdepend $\in \_$ $s$ needs and addresses not only PTSD symptoms stemming from prior trauma, but also emotional and behavioral problems related to daily stressors (Murray et al., 2018). Caregivers can be taught parenting skills in individual sessions. However, compared to the trauma-focused interventions described above, the evidence for such a common elements approach for refugee youth is much more preliminary. It has only been evaluated in a non-controlled study with refugee youth living in Somali refugee camps indicating decreases in PTSD symptoms, internalizing and externalizing problems as reported by youth and caregivers and improvements in youth-reported well-being (Murray et al., 2018).

Involvement of parents is only limited in the interventions described so far and a stronger focus on parenting may be warranted in order to effectively counter child maltreatment in the camps. In particular, our findings suggest that the mother-child relationship may be an important target for the prevention of child maltreatment in the participating families. Therefore, the contextual adaptation and evaluation of existing relational interventions that have demonstrated effectiveness in reducing child maltreatment in Western samples may be promising (Toth et al., 2013; Valentino, 2017). For the camp context, these should be brief, independent of technical equipment and ideally be delivered by non-professionals without costly and time-consuming training. While available parenting interventions in low-resource settings (Puffer et al., 2015, 2017) focus on teaching parenting knowledge and skills, interventions additionally addressing parentswell - be $\in$ gmaybeuitf $\in$ therefu $\geq$ ecampsasparents own mental health problems can continuously undermine their interactional and

parenting skills. A recent RCT with Syrian refugee parents living in Lebanon tested the effectiveness of a group-based parenting support intervention containing four sessions each to reduce parents

distress and improvetheirwell - be $\in$ gontheo $\neq h$ and and teachparent $\in$ gknow $\leq d \geq$ and skillsontheotherh and (Mil $\leq$ retal. , 2020). distress as it can be delivered by non-specialists in a group format and is currently being evaluated in resource-poor refugee camp settings (Akhtar et al., 2020; Sijbrandij et al., 2017). 
The layer at the top of the inverted pyramid comprises large-scale community-level psychosocial activities that promote children swell - be $\in g$ and stren $>$ hentheirresilience. Imp or tantly, theseshodfocusonprevention and s and adolescents resilience in their social

ecology at this stage (de Jong et al., 2015; Jordans et al., 2010), for example through sports contests, drumming and dancing sessions or praying groups (see Table 1). An overall positive effect of such joint activities is to strengthen peer relationships, which were related to better mental health in our study. A suitable setting may be child-friendly spaces, which are already implemented in the camps and provide a safe environment for children. A meta-analysis on the impact of child-friendly spaces in humanitarian settings in Ethiopia, Uganda, Iraq, Jordan, and Nepal observed an overall positive effect of these facilities on younger childrens (6 to 11 years) psychological well-being (Hermosilla et al., 2019). However, child-friendly spaces did not have an impact on adolescents ' well-being and appeared to be ineffective in connecting younger and older children to wider community resources. Here schools may provide more appropriate settings to also engage families and communities as structured psychosocial activities can be combined with activities focusing on psychoeducation and community sensitization. For instance, Jordans et al. (2013) conducted a 2-session psychoeducation intervention delivered by lay community counsellors for groups of parents of children who had screened positive for emotional and behavioral problems at school in Burundi. The intervention group showed a short-term effect in reducing child-reported externalizing problems among boys compared to the control group.

\section{Contextual factors}

In order to achieve sustainable and comprehensive reductions of risks for and improvements of Burundian refugee childrens well-being, contextual factors related to living in the camps need to be addressed as well (Miller \& Rasmussen, 2017). Our study findings support the need for prevention of structural risk factors for childrens ongoing exposure to violence within the family and community, which constitute a source of continuous trauma and thus a significant mental health risk. Another study connected to this research project found that families lower household income was related to higher levels of mothers selfreported violence against children (Hecker et al., 2020). This suggests that policies allowing refugees to work inside and outside the camps as well as livelihood programs teaching vocational skills may be fruitful to reduce economic and psychological strain on families and parents (Bermudez et al., 2018; Miller \& Rasmussen, 2017). In a similar vein, a higher educational level of fathers was related to a lower child-reported use of paternal violence against children (Hecker et al., 2020). This implies that programs which support parents in pursuing further education in the camps may also benefit families and children.

\section{Discussion}

Drawing on our epidemiological observational study with Burundian refugee families living in refugee camps, we emphasize the importance of considering both the specific need for interventions as well as contextually relevant factors of influence in order to make efficient use of scare specialist resources for mental health care for children in low-income humanitarian settings. We proposed a multi-layer mental health service model that takes into account the low prevalence of youth with severe mental health problems as well as the crucial role of family-level factors for affected youth and suggested possible interventions on each layer. In the following, we discuss concrete caveats and limitations with regard to the implementation of such a model.

While it is desirable that interventions are multi-modal to avoid addressing relevant risk factors for children`s mental health in a piecemeal fashion and overwhelming children and families through multiple different interventions at once, the lay providers of interventions should also not be overtaxed by having to learn many different treatment elements. Therefore, a specialized approach may be useful in which all providers are trained in activities related to identification, e.g. screening and psychoeducation, while they receive more specialized training in certain interventions, e.g. parent- or child-focused, and can be flexibly consulted depending on the needs of a specific child and family.

In general, our findings suggest that fathers should equally be engaged in family-level and parenting interventions despite possible policy- and cultural-level barriers prioritizing women as primary agents in childrens upbringing (Doyle et al., 2014; Panter-Brick et al., 2014). For instance, the above mentioned parenting support intervention (Miller et al., 2020) explicitly targeted both mothers and fathers and showed that it was feasible to engage men by applying several strategies: scheduling sessions in a way that they do not conflict with income-generating activities, emphasizing the intervention focus on personal well-being and incorporating fathers feedback in the implementation of the intervention, among others.

The epidemiological assessment of youths need for interventions and relevant intervention targets was fundamental for conceptualizing the proposed mental health service model. Before implementing the model a comprehensive qualitative assessment with the beneficiaries of the intervention, i.e. Burundian refugee youth and their families, community and religious leaders and other relevant stakeholder, e.g. employees of providing NGOs, doctors and teachers, should be conducted (Alisic et al., 2020; de Jong et al., 2015). This serves to identify barriers to mental health care, map human resource capacities of involved stakeholders and perceived needs and challenges related to service implementation (de Jong et al., 2015). Moreover, it entails a participatory approach involving childrens, families and communities views and perspectives in the development, implementation and evaluation of interventions (Alisic et al., 2020; Betancourt et al., 2015), facilitating the cultural adaptations of interventions by taking into account cultural concepts of parenting and mental health (Eruyar et al., 2020; Miller et al., 2020). In the Burundian context, for example, the local idioms akabonge, a set of depression-like symptoms, and ihahamuka, comprising PTSD-related reactions to traumatic experiences, have been described (Irankunda et al., 2017; Ventevogel et al., 2013). In addition to involving beneficiaries in the implementation, a transparent and comprehensible communication of the content, goals, risks and benefits of programs will reduce unrealistic expectations and concerns (Acharya et al., 2017). Finally, it is an ethical, professional and scientific duty to rigorously evaluate the effectiveness and contextual applicability of all interventions prior to dissemination to ensure that they do good rather than do harm (Allden et al., 2009; Wessells, 2009).

Limitations of the described model predominantly reflect those of the original observational study, which may have affected study findings, for example the use of instruments and cut-off scores that had not been validated in Burundian (refugee) samples as well as reporter biases such as over- and underreporting Loading [MathJax]/jax/element/mml/optable/Latin1Supplement.js _ner, et al., 2020). Moreover, as the proposed model was developed based on findings from Burundian 
refugee families living in Tanzanian refugee camps, its generalizability to other populations and contexts is limited. However, while epidemiological need assessments in similar contexts are scarce and yielded highly varying prevalence rates of mental health problems among youth (Vossoughi et al., 2018), key intervention targets in our model such as traumatic experiences, parental mental health and family violence have been shown to be relevant factors for youths mental health also in other refugee camps (Scharpf, Kaltenbach, Nickerson, et al., 2020). Thus our model may also be applicable to other refugee camp contexts, which should however be tested in the future. From a pragmatic viewpoint, the proposed model could still be difficult to implement and sustain with limited financial and specialist resources despite a strong focus on task-shifting to para-professionals (Jordans et al., 2010). As their training and supervision would make up a significant amount of the workload of available mental health professionals, the recruitment of additional specialists may be inevitable to provide sufficient care capacities for all clients. Notwithstanding, improving and promoting refugee childrens and adolescents' mental health and adjustment is worth every effort, laying the foundation of a peaceful and productive society and healthy future generations.

\section{Conclusions}

A significant task mental health service providers in humanitarian emergencies, such as refugee camps, have to face is to allocate their limited resources in a way that will benefit those who are most in need of mental health care. Taking the example of Burundian refugee families living in Tanzanian camps, we argue that an epidemiological assessment of a target group's needs and relevant factors of influence are essential in deciding how to use available resources. It is conceivable that it might appear more straight-forward and initially more time- and cost-effective to apply a service model that worked in another context without any a priori epidemiological assessment. Notwithstanding, this bears a risk of making an inefficient use of scarce resources and of undermining resilient trajectories through untargeted interventions. While the proposed care model recommends to provide interventions following a layered approach similar to previous models (Inter Agency Standing Committee (IASC), 2007; Jordans et al., 2010), it prioritizes the allocation of resources to identification of youth in need and focused interventions. All model components should be evidence-based and require rigorous evaluation before implementation.

\section{Declarations}

\section{Ethics approval and consent to participate}

The empirical study this conceptual paper draws upon was performed in line with the principles of the Declaration of Helsinki. Approval was granted by the Ethics Committee of the University of Zurich (No. 2017.10.2) and the National Institute for Medical Research in Tanzania (no. NIMR/HQ/R.8a/Vol.IX/2632).

\section{Consent for publication}

Not applicable

\section{Availability of data and materials}

Not applicable

\section{Competing interests}

The authors declare that they have no competing interests.

\section{Funding}

The empirical study this conceptual paper draws upon received funding from the North-South Cooperation of the University of Zurich [F-63212-13-01]. The funding body had no role in the design of the study, the collection, analysis, and interpretation of data and writing of the manuscripts.

\section{Authors`contributions}

FS and TH developed the concept of the manuscript. FS wrote the first draft of the manuscript and both FS and TH contributed to the final version of the manuscript.

\section{Acknowledgements}

We thank all the families in Nyarugusu, Nduta and Mtendeli whose participation in our empirical field study provided the foundation for the intervention model proposed in this manuscript. Special thanks go to Plan International Tanzania and International Rescue Committee Tanzania for providing space and resources for data collection. We are extremely grateful to our highly motivated research team, to Masath Bwire Faustine and Getrude Mkinga, Bielefeld University, to Edna Kyaruzi, Mabula Nkuba and Maregesi Machumu, Dar es Salaam University College of Education, and to Andreas Maercker and Markus Landolt, Department of Psychology, University of Zurich, for their continuous support. 
1. Acharya, B., Basnet, M., Rimal, P., Citrin, D., Hirachan, S., Swar, S., Thapa, P., Pandit, J., Pokharel, R., \& Kohrt, B. (2017). Translating mental health diagnostic and symptom terminology to train health workers and engage patients in cross-cultural, non-English speaking populations. International Journal of Mental Health Systems, 11, 62. https://doi.org/10.1186/s13033-017-0170-2

2. Akhtar, A., Giardinelli, L., Bawaneh, A., Awwad, M., Naser, H., Whitney, C., Jordans, M. J. D., Sijbrandij, M., \& Bryant, R. A. (2020). Group problem management plus (gPM+) in the treatment of common mental disorders in Syrian refugees in a Jordanian camp: Study protocol for a randomized controlled trial. BMC Public Health, 20(1), 1-8. https://doi.org/10.1186/s12889-020-08463-5

3. Alisic, E., Roth, J., Cobham, V., Conroy, R., Young, A. De, Hafstad, G., Hecker, T., Hiller, R., Kassam-Adams, N., Lai, B., Landolt, M., Marsac, M., Seedat, S., \& Trickey, D. (2020). Working towards inclusive and equitable trauma treatment guidelines: A child-centred reflection. European Journal of Psychotraumatology. https://researchportal.bath.ac.uk/en/publications/working-towards-inclusive-and-equitable-trauma-treatment-guidelin

4. Allden, K., Jones, L., Weissbecker, I., Wessells, M., Bolton, P., Betancourt, T. S., Hijazi, Z., Galappatti, A., Yamout, R., Patel, P., \& Sumathipala, A. (2009). Mental health and psychosocial support in crisis and conflict: Report of the mental health working group. Prehospital and Disaster Medicine, 24(Suppl.2), 217-227. https://doi.org/10.1017/S1049023X00021622

5. Bermudez, L. G., Parks, L., Meyer, S., Muhorakeye, L., \& Stark, L. (2018). Safety, trust, and disclosure: A qualitative examination of violence against refugee adolescents in Kiziba Camp, Rwanda. Social Science and Medicine, 200, 83-91. https://doi.org/10.1016/j.socscimed.2018.01.018

6. Betancourt, T. S., Frounfelker, R., Mishra, T., Hussein, A., \& Falzarano, R. (2015). Addressing health disparities in the mental health of refugee children and adolescents through community-based participatory research: a study in 2 communities. American Journal of Public Health, 105 Suppl, S475-82. https://doi.org/10.2105/AJPH.2014.302504

7. Catani, C., Mahendran, K., Ruf, M., Schauer, E., Elbert, T., \& Neuner, F. (2009). Treating children traumatized by war and Tsunami: A comparison between exposure therapy and meditation-relaxation in North-East Sri Lanka. BMC Psychiatry, 9(1), 22. https://doi.org/10.1186/1471-244X-9-22

8. Cohen, J. A., Mannarino, A. P., \& Deblinger, E. (2016). Treating Trauma and Traumatic Grief in Children and Adolescents. New York: Guilford.

9. de Jong, J. T. V. M., Berckmoes, L. H., Kohrt, B. A., Song, S. J., Tol, W. A., \& Reis, R. (2015). A Public Health Approach to Address the Mental Health Burden of Youth in Situations of Political Violence and Humanitarian Emergencies. In Current Psychiatry Reports (Vol. 17, Issue 7). Current Medicine Group LLC 1. https://doi.org/10.1007/s11920-015-0590-0

10. Doyle, K., Kato-Wallace, J., Kazimbaya, S., \& Barker, G. (2014). Transforming gender roles in domestic and caregiving work: preliminary findings from engaging fathers in maternal, newborn, and child health in Rwanda. Gender and Development, 22(3), 515-531. https://doi.org/10.1080/13552074.2014.963326

11. Ertl, V., \& Neuner, F. (2014). Are school-based mental health interventions for war-affected children effective and harmless? BMC Medicine, 12 (1), 84. https://doi.org/10.1186/1741-7015-12-84

12. Eruyar, S., Huemer, J., \& Vostanis, P. (2018). Review: How should child mental health services respond to the refugee crisis? Child and Adolescent Mental Health, 23(4), 303-312. https://doi.org/10.1111/camh.12252

13. Eruyar, S., Maltby, J., \& Vostanis, P. (2020). How do Syrian refugee children in Turkey perceive relational factors in the context of their mental health? Clinical Child Psychology and Psychiatry, 25(1), 260-272. https://doi.org/10.1177/1359104519882758

14. Fazel, M. (2018). Psychological and psychosocial interventions for refugee children resettled in high-income countries. Epidemiology and Psychiatric Sciences, 27(2), 117-123. https://doi.org/10.1017/S2045796017000695

15. Fazel, M., Wheeler, M., \& Danesh, J. (2005). Prevalence of serious mental disorder in 7000 refugees resettled in western countries: A systematic review. The Lancet. https://doi.org/10.1016/S0140-6736(05)61027-6

16. Hall, B. J., Puffer, E. S., Murray, L. K., Ismael, A., Bass, J. K., Sim, A., \& Bolton, P. A. (2014). The Importance of Establishing Reliability and Validity of Assessment Instruments for Mental Health Problems: An Example from Somali Children and Adolescents Living in Three Refugee Camps in Ethiopia. Psychological Injury and Law, 7(2), 153-164. https://doi.org/10.1007/s12207-014-9188-9

17. Hecker, T., Kyaruzi, E., Borchardt, J., \& Scharpf, F. (2020). Risk factors for maternal and paternal violence against children in East-African refugee families. Manuscript Submitted for Publication.

18. Hermosilla, S., Metzler, J., Savage, K., Musa, M., \& Ager, A. (2019). Child friendly spaces impact across five humanitarian settings: A meta-analysis. BMC Public Health, 19(1), 576. https://doi.org/10.1186/s12889-019-6939-2

19. Hodes, M., \& Vostanis, P. (2018). Practitioner Review: Mental health problems of refugee children and adolescents and their management. Journal of Child Psychology and Psychiatry, 60(7), jcpp.13002. https://doi.org/10.1111/jcpp.13002

20. Human Rights Watch. (2017). World Report 2017: Burundi. https://www.hrw.org/world-report/2017/country-chapters/burundi

21. Inter Agency Standing Committee (IASC). (2007). IASC on Mental Health and Psychosocial Support in Emergency Settings. https://doi.org/10.1037/e518422011-002

22. Irankunda, P., Heatherington, L., \& Fitts, J. (2017). Local terms and understandings of mental health problems in Burundi. Transcultural Psychiatry, 54(1), 66-85. https://doi.org/10.1177/1363461516689004

23. Jacob, N., Neuner, F., Maedl, A., Schaal, S., \& Elbert, T. (2014). Dissemination of psychotherapy for trauma spectrum disorders in postconflict settings: A randomized controlled trial in Rwanda. Psychotherapy and Psychosomatics, 83(6), 354-363. https://doi.org/10.1159/000365114

24. Jordans, M. J. D., Pigott, H., \& Tol, W. A. (2016). Interventions for Children Affected by Armed Conflict: a Systematic Review of Mental Health and Psychosocial Support in Low- and Middle-Income Countries. Current Psychiatry Reports, 18(1), 9. https://doi.org/10.1007/s11920-015-0648-z

25. Jordans, M. J. D., Tol, W. A., Komproe, I. H., Susanty, D., Vallipuram, A., Ntamatumba, P., Lasuba, A. C., \& de Jong, J. T. V. M. (2010). Development of a multi lnumrad nounhononial anm nuntom far ahildran in areas of political violence. International Journal of Mental Health Systems, 4. 
https://doi.org/10.1186/1752-4458-4-15

26. Jordans, M. J. D., Tol, W. A., Ndayisaba, A., \& Komproe, I. H. (2013). A controlled evaluation of a brief parenting psychoeducation intervention in Burundi. Social Psychiatry and Psychiatric Epidemiology, 48(11), 1851-1859. https://doi.org/10.1007/s00127-012-0630-6

27. Kien, C., Sommer, I., Faustmann, A., Gibson, · Lacey, Schneider, M., Krczal, E., Jank, · Robert, Klerings, I., Szelag, M., Kerschner, B., Brattström, P., \& Gartlehner, G. (2019). Prevalence of mental disorders in young refugees and asylum seekers in European Countries: a systematic review. European Child and Adolescent Psychiatry. https://doi.org/10.1007/s00787-018-1215-z

28. McMullen, J., O'Callaghan, P., Shannon, C., Black, A., \& Eakin, J. (2013). Group trauma-focused cognitive-behavioural therapy with former child soldiers and other war-affected boys in the DR Congo: a randomised controlled trial. Journal of Child Psychology and Psychiatry, 54(11), 1231-1241. https://doi.org/10.1111/jcpp.12094

29. Miller, K. E., Koppenol-Gonzalez, G. V., Arnous, M., Tossyeh, F., Chen, A., Nahas, N., \& Jordans, M. J. D. (2020). Supporting Syrian families displaced by armed conflict: A pilot randomized controlled trial of the Caregiver Support Intervention. Child Abuse and Neglect, 106, 104512. https://doi.org/10.1016/j.chiabu.2020.104512

30. Miller, K. E., \& Rasmussen, A. (2017). The mental health of civilians displaced by armed conflict: An ecological model of refugee distress. Epidemiology and Psychiatric Sciences, 26(2), 129-138. https://doi.org/10.1017/S2045796016000172

31. Morina, N., Akhtar, A., Barth, J., \& Schnyder, U. (2018). Psychiatric Disorders in Refugees and Internally Displaced Persons After Forced Displacement: A Systematic Review. Frontiers in Psychiatry, 9(SEP), 433. https://doi.org/10.3389/fpsyt.2018.00433

32. Murray, L. K., Hall, B. J., Dorsey, S., Ugueto, A. M., Puffer, E. S., Sim, A., Ismael, A., Bass, J., Akiba, C., Lucid, L., Harrison, J., Erikson, A., \& Bolton, P. A. (2018). An evaluation of a common elements treatment approach for youth in Somali refugee camps. Global Mental Health, 5, e16.

https://doi.org/10.1017/gmh.2018.7

33. Neuner, F., Onyut, P. L., Ertl, V., Odenwald, M., Schauer, E., \& Elbert, T. (2008). Treatment of Posttraumatic Stress Disorder by Trained Lay Counselors in an African Refugee Settlement: A Randomized Controlled Trial. Journal of Consulting and Clinical Psychology, 76(4), 686-694. https://doi.org/10.1037/0022-006X.76.4.686

34. Neuner, F., Schauer, M., Klaschik, C., Karunakara, U., \& Elbert, T. (2004). A comparison of narrative exposure therapy, supportive counseling, and psychoeducation for treating posttraumatic stress disorder in an african refugee settlement. Journal of Consulting and Clinical Psychology, 72(4), 579587. https://doi.org/10.1037/0022-006X.72.4.579

35. O'Callaghan, P., McMullen, J., Shannon, C., Rafferty, H., \& Black, A. (2013). A Randomized Controlled Trial of Trauma-Focused Cognitive Behavioral Therapy for Sexually Exploited, War-Affected Congolese Girls. Journal of the American Academy of Child and Adolescent Psychiatry, 52(4), 359-369. https://doi.org/10.1016/J.JAAC.2013.01.013

36. Panter-Brick, C., Burgess, A., Eggerman, M., McAllister, F., Pruett, K., \& Leckman, J. F. (2014). Practitioner review: Engaging fathers - Recommendations for a game change in parenting interventions based on a systematic review of the global evidence. Journal of Child Psychology and Psychiatry, 55(11), 11871212. https://doi.org/10.1111/jcpp. 12280

37. Panter-Brick, C., Dajani, R., Eggerman, M., Hermosilla, S., Sancilio, A., \& Ager, A. (2018). Insecurity, distress and mental health: experimental and randomized controlled trials of a psychosocial intervention for youth affected by the Syrian crisis. Journal of Child Psychology and Psychiatry, 59(5), 523-541. https://doi.org/10.1111/jcpp.12832

38. Puffer, E. S., Annan, J., Sim, A. L., Salhi, C., \& Betancourt, T. S. (2017). The impact of a family skills training intervention among Burmese migrant families in Thailand: A randomized controlled trial. PloS One, 12(3), e0172611. https://doi.org/10.1371/journal.pone.0172611

39. Puffer, E. S., Green, E. P., Chase, R. M., Sim, A. L., Zayzay, J., Friis, E., Garcia-Rolland, E., \& Boone, L. (2015). Parents make the difference: a randomizedcontrolled trial of a parenting intervention in Liberia. Global Mental Health, 2, e15. https://doi.org/10.1017/gmh.2015.12

40. Reed, R. V., Fazel, M., Jones, L., Panter-Brick, C., \& Stein, A. (2012). Mental health of displaced and refugee children resettled in low-income and middleincome countries: Risk and protective factors. The Lancet, 379(9812), 250-265. https://doi.org/10.1016/S0140-6736(11)60050-0

41. Reliefweb. (2018). Highlighted Underfunded Situations in 2018, September 2018. https://reliefweb.int/report/world/highlighted-underfunded-situations2018-september-2018

42. Robjant, K., \& Fazel, M. (2010). The emerging evidence for Narrative Exposure Therapy: A review. Clinical Psychology Review, 30(8), 1030-1039. https://doi.org/10.1016/j.cpr.2010.07.004

43. Saile, R., Ertl, V., Neuner, F., \& Catani, C. (2016). Children of the postwar years: A two-generational multilevel risk assessment of child psychopathology in northern Uganda. Development and Psychopathology, 28(2), 607-620. https://doi.org/10.1017/S0954579415001066

44. Saltzman, W. R., Layne, C. M., Steinberg, A. M., Arslanagic, B., \& Pynoos, R. S. (2003). Developing a culturally and ecologically sound intervention program for youth exposed to war and terrorism. In Child and Adolescent Psychiatric Clinics of North America (Vol. 12, Issue 2, pp. 319-342). W.B. Saunders. https://doi.org/10.1016/S1056-4993(02)00099-8

45. Scharpf, F., Kaltenbach, E., Nickerson, A., \& Hecker, T. (2020). A systematic review of socio-ecological factors contributing to risk and protection of the mental health of refugee children and adolescents. Clinical Psychology Review, 101930. https://doi.org/https://doi.org/10.1016/j.cpr.2020.101930

46. Scharpf, F., Kyaruzi, E., Landolt, M. A., \& Hecker, T. (2019). Prevalence and co-existence of morbidity of posttraumatic stress and functional impairment among Burundian refugee children and their parents. European Journal of Psychotraumatology, 10, 1676005.

https://doi.org/10.1080/20008198.2019.1676005

47. Scharpf, F., Mkinga, G., Masath, F. B., \& Hecker, T. (2020). A socio-ecological analysis of risk, protective and promotive factors for the mental health of Burundian refugee children living in refugee camps. European Child \& Adolescent Psychiatry. https://doi.org/https://doi.org/10.1007/s00787-020-01649-

Loading [MathJax]/jax/element/mml/optable/Latin1Supplement.js

Page 9/11 
48. Scharpf, F., Mkinga, G., Neuner, F., Maregesi, M., \& Hecker, T. (2020). Fuel to the fire: The escalating interplay of attachment and maltreatment in the transgenerational transmission of psychopathology in refugee families living in refugee camps. Development and Psychopathology, 1-14. https://doi.org/10.1017/S0954579420000516

49. Scharpf, F., Mueller, S. C., Masath, F. B., Nkuba, M., \& Hecker, T. (2020). Psychopathology mediates between maltreatment and memory functioning in Burundian refugee youth. Manuscript Submitted for Publication.

50. Sijbrandij, M., Acarturk, C., Bird, M., Bryant, R. A., Burchert, S., Carswell, K., de Jong, J. T. V. M., Dinesen, C., Dawson, K. S., El Chammay, R., van Ittersum, L., Jordans, M. J. D., Knaevelsrud, C., McDaid, D., Miller, K. E., Morina, N., Park, A.-L., Roberts, B., van Son, Y., ... Cuijpers, P. (2017). Strengthening mental health care systems for Syrian refugees in Europe and the Middle East: integrating scalable psychological interventions in eight countries. European Journal of Psychotraumatology, 8(sup2), 1388102. https://doi.org/10.1080/20008198.2017.1388102

51. Silove, D., Ventevogel, P., \& Rees, S. (2017). The contemporary refugee crisis: an overview of mental health challenges. World Psychiatry, 16(2), $130-139$. https://doi.org/10.1002/wps.20438

52. Stevens, A., \& Gillam, S. (1998). Needs assessment: From theory to practice. In British Medical Journal (Vol. 316, Issue 7142, pp. 1448-1452). BMJ Publishing Group. https://doi.org/10.1136/bmj.316.7142.1448

53. Tol, W. A., Komproe, I. H., Jordans, M. J. D., Ndayisaba, A., Ntamutumba, P., Sipsma, H., Smallegange, E. S., Macy, R. D., \& de Jong, J. T. V. M. (2014). School-based mental health intervention for children in war-affected Burundi: a cluster randomized trial. BMC Medicine, $12(1), 56$. https://doi.org/10.1186/1741-7015-12-56

54. Toth, S. L., Gravener-Davis, J. A., Guild, D. J., \& Cicchetti, D. (2013). Relational Interventions for child maltreatment: Past, present, and future perspectives. Development and Psychopathology, 25(2), 1601-1617. https://doi.org/10.1017/S0954579413000795

55. UNHCR. (2018a). Burundi Situation: Regional Inter Agency Plan of Action for the Protection of Refugee Children. https://www.unhcr.org/5a683fdf7.pdf 56. UNHCR. (2018b). Global Trends: Forced Displacement in 2017. https://www.unhcr.org/5b27be547.pdf

57. Uvin, P. (2009). Life after violence: A people's story of Burundi. Zed Books.

58. Valentino, K. (2017). Relational Interventions for Maltreated Children. Child Development, 88(2), 359-367. https://doi.org/10.1111/cdev.12735

59. Ventevogel, P., Jordans, M. J. D., Reis, R., \& de Jong, J. T. V. M. (2013). Madness or sadness? Local concepts of mental illness in four conflict-affected African communities. Conflict and Health, 7(1), 3. https://doi.org/10.1186/1752-1505-7-3

60. Vossoughi, N., Jackson, Y., Gusler, S., \& Stone, K. (2018). Mental Health Outcomes for Youth Living in Refugee Camps. Trauma, Violence, \& Abuse, 19(5), 528-542. https://doi.org/10.1177/1524838016673602

61. Wessells, M. G. (2009). Do No Harm: Toward Contextually Appropriate Psychosocial Support in International Emergencies. American Psychologist. https://doi.org/10.1037/0003-066X.64.8.842

\section{Figures}




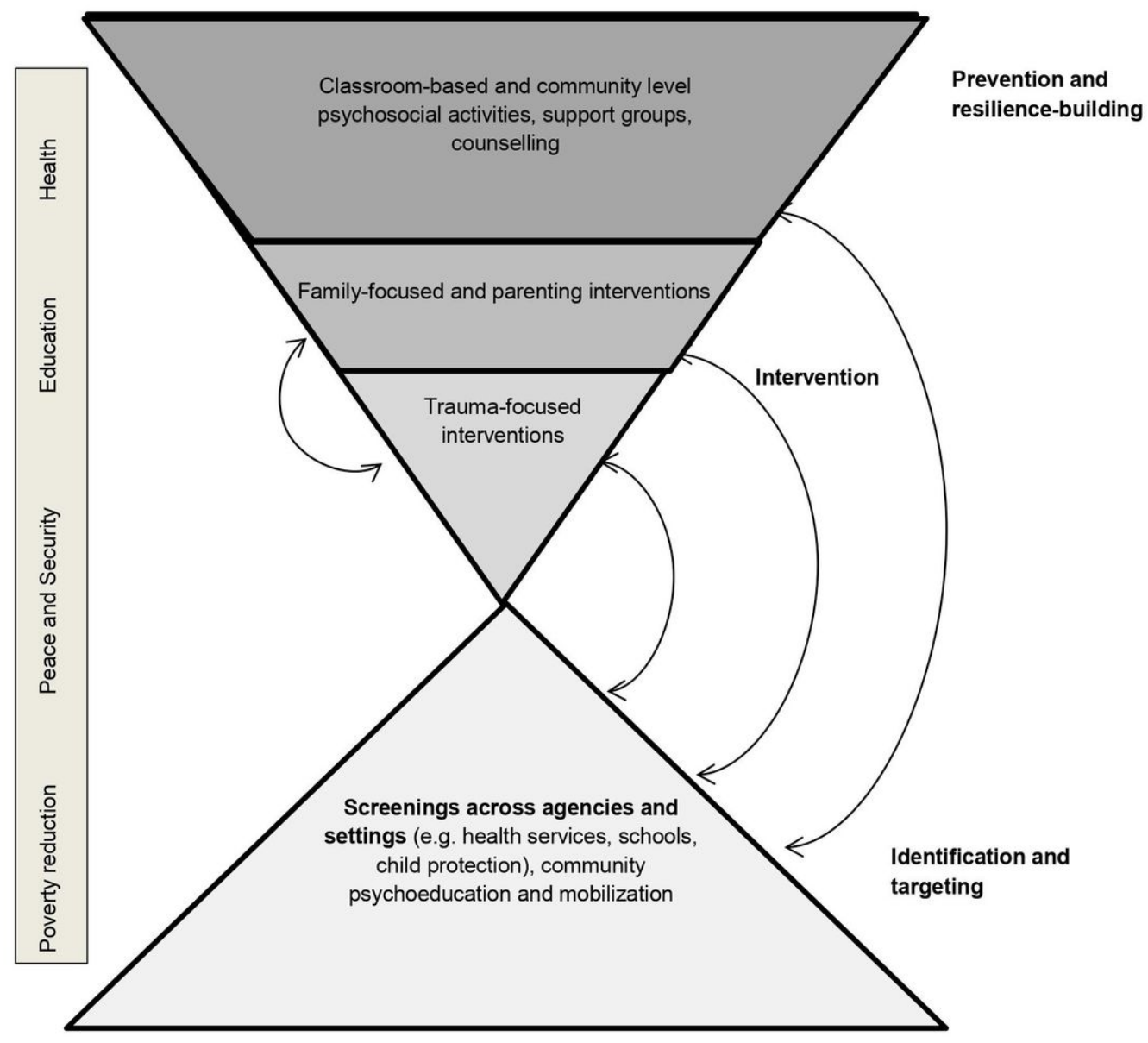

Figure 1

Multi-layered mental health service model for Burundian refugee youth living in Tanzanian refugee camps (adapted from Jordans et al., 2010). 